\title{
A INSTITUCIONALIZAÇÃO dO FUNK CARIOCA E A INVENÇÃO CRIATIVA DA CULTURA*
}

\author{
The institutionalization offunk carioca and culture as creative \\ invention
}

MYLENE MIZRAHI**

RESUMO

$\mathrm{O}$ artigo mostra o modo criativo com que o funk carioca respondeu ao processo de institucionalização pelo qual veio passando na última década. Essa institucionalização se faz acompanhar de uma tentativa de imobilização e seleção de determinados significados em detrimento de outros, gerando como desdobramento uma maior legitimação do funk como manifestação cultural a partir da neutralização de alguns de seus traços subversivos. Contudo os sujeitos funk, em sua vontade de fazer seus saberes e criações circularem, concedem em contrapartida respostas criativas às demandas da sociedade envolvente. Partimos das letras das músicas e seu significado semântico para chegarmos ao corpo e à sonoridade. $\mathrm{O}$ artista funk busca o caminho da ambiguidade, afirmando sua identidade e diferença ao mesmo tempo em que moldando suas produções e tornando-as mais permeáveis ao gosto oficial. O funk se transforma mantendo-se fiel a si mesmo.

Palavras-chave: Estética. Corpo. Som. Criatividade. Dança do passinho.

\section{ABSTRACT}

The article shows the creative way funk carioca responds the institutionalization process by which it came through the last decade. This institutionalization is accompanied by an immobilization and selection of certain meanings in an attempt to turn funk more legitimate whereas some of its subversive traits are neutralized. However, the funk subjects in their desire to make their knowledge and creations circulate give in contrast creative responses to the demands of the surrounding society. We depart from the lyrics

\footnotetext{
"Este artigo deriva da comunicação que apresentei no GT 19: "Memória Social, museus e patrimônios: novas construções de sentidos e experiências de transdisciplinaridade", ocorrido no $36^{\circ}$ Encontro Anual da ANPOCS, em 2012. Agradeço à Els Lagrou a sugestão de problematizar a institucionalização do funk carioca e aos comentários dos participantes do grupo de trabalho.

**Doutora pelo Programa de Pós-Graduação em Sociologia e Antropologia do Instituto de Filosofia e Ciências Sociais da Universidade Federal do Rio de Janeiro (PPGSA-IFCS-UFRJ). Artigo resultante de pesquisa de pósdoutorado do tipo PNPD/Institucional, financiada por bolsa CAPES.
} 
and its semantic meaning to get to the body and sound. The funk artist seeks the path of ambiguity, stating both their identity and difference while shaping their productions in order to make them more permeable to the official taste. Funk transforms and stays true to itself.

Keywords: Aesthetics. Body. Sound. Creativity. Passinho dance.

\section{Introdução}

Neste artigo quero refletir sobre o processo de institucionalização pelo qual vem passando o funk carioca nos últimos anos. Testemunhei este processo ao longo da pesquisa empírica que alicerçou minha tese de doutorado, originando a etnografia $A$ estética funk carioca: criação e conectividade em Mr. Catra, testemunho que em alguns momentos se traduz no caráter reflexivo que apresentará a presente narrativa. Inserir-me-ei no próprio processo que descreverei, falando a partir do trabalho de campo que conduzi, guiada por meus interesses sobre arte, beleza e criatividade. Portanto, um dos aspectos que trarei é o modo pelo qual somos capturados por estas políticas de imobilização de símbolos e significados mesmo que não estejamos ativamente engajados nelas.

Ainda que eu tenha tratado da criatividade musical e da criação artística em um sentido estrito - enquanto produzida por artistas propriamente ditos, os músicos - um de meus focos principais recaiu sobre os objetos materiais que compõem a estética corporal funk. Como resultado, estabeleci uma discussão sobre a criação musical acompanhada de outra mais relativa aos estudos de cultura material, à antropologia da arte e à antropologia do consumo. Dessa perspectiva, ao pensar o corpo, pensei no sujeito funk como criativo, produzindo também arte, sendo assim tomado como um artista definido em sentido amplo. O sujeito funk foi apreendido a partir de sua habilidade na manipulação de símbolos da cultura, tanto musical quanto corporal.

De modo sucinto, o que mostrei foi como toda uma produção estética - fosse esta a música e a letra das canções ou a moda de vestuário e os adornos corporais - é engendrada de modo a produzir conectividade (MIZRAHI, 2010a, 2014a). Por conectividade refiro-me, a partir de Strathern (2004), ao tipo de socialidade que a relação social ambígua é capaz de produzir. O sujeito criativo funk, mesmo que estabeleça uma relação conflituosa com a sociedade envolvente e suas partes, não a recusa. Busca, outrossim, estabelecer conexões parciais com a sociedade formal, com seus sujeitos, com as distintas partes da cidade e os diferentes gostos que estas produzem. O sujeito funk se conecta sem se deixar amalgamar, mantendo diferença a partir da similaridade. De maneira análoga foi pensado o todo. O Rio de Janeiro foi apreendido como uma cidade ciborgue cujas diferentes partes geográficas e sociais foram objetificadas por seus diferentes gostos estéticos. As partes estão em contato, 
mas não se fundem. A cidade está conectada, ao invés de partida, como quis a metáfora que tanto ressoou nos anos 1990 (MIZRAHI, 2013a).

É portanto o tema das relações entre o espaço urbano e a produção de estéticas que conduzirá a minha reflexão aqui. Abordaremos uma estética "popular", definida não enquanto manifestação que resulta de fazeres e saberes "tradicionais" mas no que se refere a uma produção voltada para o consumo de massa ou que é apropriada de maneira massiva. Falar em institucionalização do funk nos ajudará a ver não apenas o modo pelo qual os agentes oficiais e governamentais atuam na seleção do que é ou não é cultura, mas nos colocará em contato também com as estratégias de auto-apresentação imobilizadas pelo próprio sujeito criativo funk. Tratam-se assim de estratégias de visibilização para a sociedade como um todo, de modo que nossa análise se iniciará na música para chegar ao corpo e seus modos de se fazer ver e de se inserir no espaço urbano carioca. Essa passagem da música para o corpo se relaciona ao que me parece ser mais propriamente distintivo do funk. De um lado, veremos a centralidade que a agência do som adquire na produção da música face a seu aspecto narrativo. De outro lado, destacaremos o papel que o corpo desempenha na definição do sujeito funk.

Discorrerei assim sobre o processo de imobilização de significados da música funk e seu conteúdo semântico para em seguida vermos que a dança e o movimento corporal findam também por se impor nesse mesmo processo. Esta imobilização de sentidos e representações coloca em ação uma concepção oficial de cultura mas igualmente a coloca em xeque, questionando-a ao invés de promover a sua cristalização. As ambigüidades que derivam dessa seleção de significados e da ressignificação de sentidos são incorporadas ao próprio processo de invenção da cultura a partir da criatividade do sujeito funk. Em outros termos, se de um lado veremos esse processo de legitimação objetificar uma noção de cultura que faz coincidir reivindicações de identidade coletiva com demandas governamentais e suas políticas públicas, de outro vemos a própria dinâmica da cultura transformar o funk a partir do englobamento da noção oficial de cultura. Notaremos assim as simultâneas continuidades e descontinuidades existentes entre o processo de institucionalização e legitimação do funk e aquelas que regem a cultura.

\section{As ambiguidades que cercam o funk}

O funk carioca é um ritmo musical de origem norte-americana que chegou ao Rio de Janeiro na década de 1980. O lócus principal de sua execução se deu em bailes de dança que ocorriam inicialmente nas áreas privilegiadas da cidade, em particular na Zona Sul, e que posteriormente migraram para as suas áreas periféricas. É mais propriamente nas favelas 
que a ressignificação do ritmo estrangeiro ocorre, tornando-se manifestação cultural fortemente associada aos jovens das classes populares da cidade. Hoje é possível dizer que o ritmo, mesmo que majoritariamente consumido por estes mesmos jovens, alcançou uma circulação tal que lhe permitiu tornar-se um dos símbolos mais loquazes do Rio de Janeiro, tanto em âmbito nacional como em contextos estrangeiros.

Este foi um percurso espontâneo e compatível com a própria dinâmica da cultura brasileira, que transforma manifestações culturais populares em símbolos de identidade nacional, com argumentou Fry (1982). Contudo, nos últimos anos foi possível acompanhar uma formalização desse andamento por meio do processo de institucionalização do movimento musical colocado em curso por ações governamentais - municipais e estaduais - e que opera ainda englobando iniciativas voluntárias e independentes. Estas ações formais podem ser vistas nos projetos que a FUNARTE vêm financiando (FORNACIARI, 2011), nos editais de apoio à criação artística e aos bailes funk da Secretaria de Cultura do Estado, no festival intitulado Batalha do Passinho $^{1}$ e ainda na recepção de minha própria tese de doutorado pelos órgãos públicos. O funk, já conhecido em ambientes globais como música eletrônica brasileira, passava agora por um movimento que visava convertê-lo, desta vez oficialmente, à representação de brasilidade. Ao mesmo tempo este processo revela o modo ainda ambivalente com que este mesmo poder oficial se relaciona com o funk.

Venho investigando o universo estético funk desde 2002, com um olhar inicialmente voltado para as elaborações de moda e beleza, tanto feminina e masculina, olhar este instigado justamente pela diferença que ele mostrou em relação ao que pode ser chamado de gosto oficial. Da pesquisa inicial de 2002 derivei na pesquisa de mestrado e todo esse período de investigação culminou na tese de doutorado, defendida em 2010 (MIZRAHI, 2010a). Em 2011 a tese ganhou o primeiro prêmio do Concurso Maurício de Almeida Abreu, que avaliou teses e dissertações que permitissem entender o Rio de Janeiro e facilitassem a adoção de ações de políticas públicas para a cidade, como constou em seu edital. O concurso foi concebido pelo Instituto Municipal de Urbanismo Pereira Passos, IPP-Rio, ligado à Secretaria Municipal de Urbanismo do Rio de Janeiro. O fato é que inscrevi a tese sem muita crença que ela tivesse lugar naquele fórum, mas o fiz por força do dever.

Mr. Catra, o cantor de funk a partir do qual tracei a rede de relações que conformou o universo funk que explorei em minha pesquisa de doutorado, ainda durante o trabalho de campo, expressou percepção semelhante, parecendo pensar de maneira análoga. Em uma tarde no estúdio de gravação, antecipando a desconfiança que eu ainda teria, o artista disseme que o trabalho que eu fazia era "muito louco". Era muito bom, e poderia até ser premiado, considerou ele. Contudo, continuou, o Rio de Janeiro não estava preparado para o que eu traria. Tanto eu como Mr. Catra nos enganamos, mas apenas parcialmente. Eu me enganei ao não apostar no potencial de recepção que o trabalho possuía para concorrer pelo prêmio,

${ }^{1}$ Competição de dançarinos funk oriundos de diferentes favelas do Rio de Janeiro criado em 2011. 
e a verdade é que o inscrevi já no limite do prazo. Na ordem de inscrição, ele era o penúltimo da lista. E Mr. Catra, que acertou que ele poderia ser premiado, acertou igualmente na resistência que o funk poderia ainda apresentar aos órgãos e gostos oficiais. Pois se a premiação dizia que o Rio de Janeiro estava sim "preparado" para receber os conhecimentos que o funk nos trazia ela também nos mostrou as ambiguidades com que isso se deu.

A cerimônia de premiação ocorreu no auditório do Jornal O Globo, com a presença do prefeito Eduardo Paes, de cujas mãos recebi o prêmio. Ambiente, portanto, mais do que hegemônico. Alguns dias antes de a cerimônia ocorrer, a assessoria de imprensa do IPP fez contato comigo fazendo saber que teriam muito gosto na presença de Mr. Catra, e eu lhes respondi que já o convidara, mas que ainda aguardava a sua resposta. $\mathrm{O}$ artista, ao fim, não compareceu, em função de seus muitos compromissos profissionais. Mas o que realmente resultou curioso, e que nos interessa para a discussão que aqui empreendemos, foi a apreensão que a mesma assessoria de imprensa externou alguns dias após ter convidado Mr. Catra para cantar junto ao coral de funcionários públicos da prefeitura. Temiam que o artista, ao subir ao palco, fizesse alguma intervenção transgressora, como é próprio de suas performances artísticas e de sua própria persona. ${ }^{2}$

Mr. Catra mescla em seus shows odes ao consumo de maconha e álcool, canções eróticas - a chamada putaria - e louvores a deus. Catra, o artista, é conhecido como "rei da putaria", e mantém diferentes relações amorosas, que coaduna com o casamento de quase duas décadas com Sílvia. Com sua esposa ele teve três filhos que se somam aos muitos outros oriundos de relações com diferentes parceiras. Filhos que circulam muito à vontade na residência que o artista mantém com Sílvia, o que nos concede uma mostra do modo de vida desafiador dos valores hegemônicos da sociedade brasileira que este núcleo familiar leva. Esta rebeldia sempre acompanhou Mr. Catra, que nos anos 1990 e inícios dos anos 2000 se destacou como nome proeminente do funk proibido. É ainda esta rebeldia que hoje Mr. Catra canta por meio de suas intervenções irônicas e suas paródias musicais. E é esta mesma rebeldia que responde pela estratégia do choque com que atua o próprio funk, desestabilizando o gosto e os valores estabelecidos. Esta relação de imbricamento entre pessoa individual, criação artística e cultura poderá ser aferida pelas letras das músicas que trarei mais adiante.

Tomaremos assim o caminho apontado pelo funk e por seus artistas, apostando na ambiguidade que os regem e que estabelece uma via de mão dupla entre eles e a sociedade envolvente. Pois de um lado vimos a ambivalência com que o gosto oficial se relaciona com o funk, explicitada pelo receio que uma possível performance de Mr. Catra gerou nos organizadores de uma cerimônia de premiação de um trabalho sobre o fazer artístico do

\footnotetext{
${ }^{2}$ Outros exemplos do modo ambíguo com que o poder público se relaciona com o funk concernem alguns projetos contemplados pelos editais da Secretaria de Cultura do Estado. Um deles diz respeito à proibição de realização de uma roda de funk. O outro é dado pela dificuldade de liberação do Baile da Chatuba pela UPP local. Estes dados foram apresentados respectivamente por Rossi Alves e Adriana Facina e Carlos Palombini em suas comunicações no II Simpósio de Pesquisadores do Funk Carioca.
} 
próprio artista, conduzida por representantes do poder oficial em moldes e ambientes hegemônicos. Esta ambiguidade, por sua vez, é correspondida pelo funk através do modo conectivo com que este movimento musical, enquanto projeto estético, se relaciona com o restante da cidade.

Este modo ambíguo com que o funk se relaciona com o gosto oficial pode ser acessado por meio das ironias e paródias de Mr. Catra, que se apresenta em diferentes ambientes sociais do Rio de Janeiro, e do Brasil, cantando basicamente o mesmo repertório de músicas. E é nas casas mais "elitizadas", aquelas frequentadas pelas camadas médias e localizadas em espaços "oficiais", que ele faz uma performance através da qual ri do outro em seus próprios redutos, sempre avisando: "daqui pra frente é só cultura". Mr. Catra, ao parodiar a MPB ou o rock brasil, invariavelmente erotizando-os, contrasta duas noções de cultura, uma de caráter nacional e estabelecida e outra popular e pouco valorizada.

Vejamos Mr. Catra ao parodiar, por exemplo, a música Tédio do grupo Biquíni Cavadão. A música original trata do tédio que abate um rapaz que cogita cometer suicídio. Já na nova versão o que se comete não é um suicídio mas um adultério.

\author{
Sabe estes dias em que horas dizem nada? \\ E você não troca o pijama \\ Preferia estar na cama \\ Um dia, a monotonia tomou conta de mim \\ É o tédio \\ Cortando os meus programas \\ Esperando o meu fim \\ Sentado no meu quarto \\ O tempo voa \\ Lá fora a vida passa \\ E eu aqui à toa \\ Eu já tentei de tudo \\ Mas não tenho remédio \\ Pra livrar-me desse tédio ${ }^{3}$ \\ Sabe esses dias que tu acorda de ressaca? \\ [Muito louco, doidão] \\ Sua roupa tá cheia de lama \\ E a cachorra tá na cama \\ É o dia que a orgia tomou conta de mim \\ Eu saio com o Brancão, Beto da Caixa, o Leo \\ Fumando doidinho \\ [Vamo pra onde?]
}

\footnotetext{
${ }^{3}$ Tédio, do grupo Biquíni Cavadão, constante no álbum Cidades em Torrente, 1986. Observo que todas as letras foram por mim transcritas ao longo da pesquisa, com exceção das letras dos exemplares do rock brasil.
} 
$\mathrm{Na} 4 \mathrm{X} 4$ a gente zoa

Uísque Red Bull

Quanta mulher boa

O pau ficando duro

O bagulho tá sério

Vai rolar o adultério

Sua mina só reclama

E tira a sua paz?

Ela é chata demais

Procura a profissional

Meu mano

Que ela sabe o que faz

É uma coisa louca

Quica, quica

Em cima de mim

Antes, durante, depois

É tesão

Até o fim

$\mathrm{Na} 4 \mathrm{X} 4$ o tempo voa

Uísque Red Bull

Quanta mulher boa

O pau ficando duro

O bagulho ta sério

Vai rolar o adultério ${ }^{4}$

Mas não é apenas no universo da música que vemos uma manifesta ambigüidade da estética funk. O corpo é suporte para outro importante exemplo. O estilo de cabelos femininos valorizado, como mostrei em outra ocasião (MIZRAHI, 2012a), é elaborado por meio de tratamentos químicos, como o relaxamento, ou é alcançado por meio da incorporação de extensões de cabelos, o chamado "mega hair". Os cabelos a que se chega não são nem lisos ou "moles", como é o cabelo da mulher branca, nem crespo como aquele tradicionalmente associado ao negro. Buscam-se cabelos ambíguos, cabelos que não reproduzem nem a estética branca e hegemônica nem tampouco cabelos que localizem suas portadoras no lugar da falta e da ausência. Junto com a beleza, busca-se desfazer a associação entre renda, classe e cor da pele, uma sobreposição que recorrentemente se faz no Brasil. Elege-se assim o cabelo anelado, que através da ambigüidade de sua aparência, nem branco nem negro, evita a fixidez identitária.

${ }^{4}$ Adultério, de Mr. Catra. Arquivo sonoro em formato eletrônico cedido pelo artista à pesquisadora. 


\section{Cultura, "cultura" e a institucionalização do funk}

Para fins analíticos, podemos propor uma escala para as transformações pelas quais vem passando o funk carioca enquanto gênero musical, tomando como seu momento primeiro os chamados raps de contexto. Estas são músicas cujas letras produzem uma crônica de tom não apenas politicamente correto sobre o dia-a-dia dos habitantes da favela mas efetivamente mais politizado, se consideramos uma definição formal de política. Em um momento intermediário teríamos of funk proibido que, de modo amplo, narra as ações ilícitas dos traficantes de drogas e as tensas relações envolvendo a polícia, o bandido e o "playboy". ${ }^{5}$ E contemporaneamente teríamos a putaria, músicas cujas letras nomeiam os órgãos sexuais e descrevem de modo fisiológico as relações eróticas entre os gêneros feminino e masculino, o que pode ser feito de maneira explícita ou velada, quando recorre-se ao uso do duplosentido.

Para conceder uma ideia do contraste que estes três sub-gêneros produzem, reproduzo abaixo a letra de três canções: a primeira é um rap de contexto, a segunda uma proibidão e a terceira uma produção de putaria.

Eu só quero é ser feliz Andar tranqüilamente na favela onde eu nasci, é $\mathrm{E}$ poder me orgulhar $\mathrm{E}$ ter a consciência que o pobre tem seu lugar (Fé em Deus... DJ)

Minha cara autoridade, eu já não sei o que fazer Com tanta violência eu sinto medo de viver Pois moro na favela e sou muito desrespeitado A tristeza e a alegria aqui caminham lado a lado

Eu faço uma oração para uma santa protetora Mas sou interrompido a tiros de metralhadora Enquanto os ricos moram numa casa grande e bela $O$ pobre é humilhado, esculachado na favela Já não aguento mais essa onda de violência Só peço, autoridade, um pouco mais de competência

Eu só quero é ser feliz Andar tranqüilamente na favela onde eu nasci E poder me orgulhar E ter a consciência que o pobre tem o seu lugar

Diversão hoje em dia não podemos nem pensar Pois até lá nos bailes eles vêm nos humilhar Ficar lá na praça, que era tudo tão normal Agora

5 "Playboy", sinteticamente, é categoria nativa que designa os jovens bem nascidos das camadas médias cariocas. 
virou moda a violência no local Pessoas inocentes, que não têm nada a ver Estão perdendo hoje o seu direito de viver Nunca vi cartão postal que se destaque uma favela Só vejo paisagem muito linda e muito bela Quem vai pro exterior da favela sente saudade $O$ gringo vem aqui e não conhece a realidade Vai pra Zona Sul pra conhecer água de coco $\mathrm{E}$ o pobre na favela, vive passando sufoco Trocaram a presidência, uma nova esperança Sofri na tempestade, agora eu quero a bonança $O$ povo tem a força, só precisa descobrir Se eles lá não fazem nada, faremos tudo daqui.

Eu só quero é ser feliz Andar tranqüilamente na favela onde eu nasci $E$ poder me orgulhar E ter a consciência que o pobre tem o seu lugar ${ }^{6}$ (CIDINHO; DOCA, 2009).

FP me deu um papo

Deu um toque no radinho

Pediu uma XT

E também uma Dobló vinho

O bonde foi na pista

Nem quero falá mais nada

Me dá logo o segredo

Se não te jogo na mala

Os irmão tá ligado

Você vai ficá fudido

Se tivé cu criança

Tu vai passá batido

Já peguei sua chave

Seu segredo e o documento

Teu carro tá na Chatuba

Dentro do estacionamento

Se tu não tá ligado

Eu vou logo te explicar

Eu não tirei a roda

E nem tirei o ar,

Sabe por quê?

${ }^{6}$ Rap da Felicidade, de Cidinho e Doca, constante do álbum Web Hits, v. 1, 2009. 
É encomenda, encomenda

Não podemos arranhá

Encomenda, encomenda

Passa teu carro!

Oi, é encomenda, encomenda

Não podemos arranhá

Ah!, é encomenda, encomenda

Passa a tua moto pra cá

FP me deu um papo

Deu um toque no radinho

Que qué uma Ornette

E uma Dobló vinho

Nosso bonde foi pa pista

Todo boladão

Foi com vários bicos

E um carro sangue bom

O bonde tá revoltado

Eu não quero briga

essa vai $p u$ Jansen,

FP e pu Naíva

Oi, oi mano Pufa

Mano MK

O bonde tá perverso

Pronto pa te derrubá

Se liga no papo reto

Tu vai passá mal

O bonde tá partindo

Lá $p u$ Banco Central

Manda o dinheiro todo

Preste atenção

Oi esse é o novo funk

Eu mando no cha...

É encomenda, encomenda

Não podemos arranhá 
Encomenda, encomenda

Manda seu carro pra cá

Se tu não se ligou

Ou se tu ainda não viu

Fecharam a Marechal Rondon

E fecharam a Brasil

Os moleke bolado

Olha aqui tu não se mete

Trouxeram uma Pajero

Um Corolla e uma Hornet

O bagulho é doidão

Vê se experimenta

O bonde vai na pista

Mas só pega de encomenda

É encomenda, encomenda

Aí?!

Aí eu te explico

Se liga aqui, ó

O bonde já deu o papo

Tu vai ficá fudido

Se tivé cu criança

Tu vai passá batido

Que o bagulho é doidão

E os moleke tão bolado

E quando vão na pista

Só pega encomendado

É encomenda, encomenda...

É encomenda, encomenda...

Aí vem assim, ó

A pedido do FP

Pra toda a rapaziada

Chegando no Chatubão

Atividade dobrada 
A pedido dos irmão

Pra toda a rapaziada

Chegando aqui no Complexo

Atividade dobrada

De dia, até de tarde

De noite, de madrugada

Chegô aqui no Complexo

Atividade dobrada ${ }^{7}$ (FRANK; TICÃO, 2007).

Hoje eu tô facim, hoje

Hoje eu tôfacim, hoje

Vou estourar seu cabacinho

Vou estourar seu cabacinho

Vou estourar seu cabacinho

Pode vim que eu tô facinho

Hoje eu tô facim, hoje

Hoje eu tôfacim, hoje

Eu sou Mágico MC

Represento toda hora

Vou tirando devagar

É minha piroca da cartola

Hoje eu tô facim, hoje

Hoje eu tôfacim, hoje

Vou estourar seu cabacinho

Vou estourar seu cabacinho

Vou estourar seu cabacinho

Pode vim que eu tô facinho

Vai mulher não fique assim

Vem que vem, vem rebolando

Rebolando, rebolando, rebolando

Porque hoje eu tô facim ${ }^{8}$ (MÁGICO, 2008).

\footnotetext{
${ }^{7}$ Toque no radinho, de MC Frank e MC Ticão. <https://www.youtube.com/watch?v=RgnJxTpeh68>.

${ }^{8}$ Hoje eu tô facinho, de MC Mágico. <https://www.youtube.com/watch?v=vfkGFcc0jPY>.
} 
Com o governo Sérgio Cabral e com a gestão do prefeito Eduardo Paes, começa a se tornar evidente o interesse das secretarias de cultura e de educação em incorporar o funk às suas práticas, fosse como instrumento mediador de suas ações e políticas públicas fosse como manifestação privilegiada da cultura carioca. Inicialmente, o funk pareceu oferecer a oportunidade de se constituir um mediador entre o professor, o aluno e o próprio ambiente escolar, sendo utilizado como instrumento facilitador de medidas direcionadas à educação de ensinos fundamental e médio em escolas públicas. Nesse contexto, o Colégio Estadual José Leite Lopes/NAVE Oi Futuro sediou o Red Bull Funk-se em julho de 2009. O evento durou três dias, ocupou o auditório da escola com palestras de artistas e acadêmicos e com oficinas para aprendizes de artistas. O Colégio Estadual José Leite Lopes/NAVE Oi é uma escola modelo, desenhada em parceria com a companhia de telecomunicações Oi e tem por objetivo criar novos formatos de ensino baseados fundamentalmente nas novas tecnologias digitais ao mesmo tempo que capacitando seus alunos para profissões em torno destas novas tecnologias de comunicação e informação.

Em seguida o próprio funk passou ser a alvo de políticas públicas que contribuíram para o reconhecimento do "funk como cultura". Toda esta negociação culminou precisamente na promulgação de duas leis pela Assembléia Legislativa do Estado do Rio de Janeiro. O então candidato à prefeitura do Rio de Janeiro nas eleições de 2012, Marcelo Freixo, esteve diretamente ligado ao processo de aprovação dessas leis. Uma dessas leis revogou uma outra, anterior, que estabelecia normas para a realização de raves e bailes funk, mas que na prática inviabilizava a realização destes últimos. A outra dessas leis interessa mais propriamente aos propósitos da discussão que aqui estabelecemos e define o funk como "movimento cultural", reforçando que daquele momento em diante os assuntos relativos ao mesmo deveriam ser "prioritariamente" tratados pelos órgãos de cultura do Estado.

Desde 2002 venho realizando trabalho de campo intensivo entre os consumidores e produtores de funk carioca, e foi com alguma apreensão que acompanhei esta movimentação. Em síntese me questionava em que medida todo o esforço de inclusão do funk não o obrigaria a fugir de seus próprios ideias estéticos e cosmológicos.

Participei de discussões, fui convidada a dar entrevistas sobre o tema, conversei e debati com lideranças funkeiras que participaram e participam do que se configurou como uma possível institucionalização do funk carioca. O que me mobilizou foi o que me pareceu uma tentativa de normatização do funk, com o os valores e gostos oficiais agindo de modo significativo nesse processo que acompanhava tanto as demandas dos órgãos governamentais como fazia eco às reivindicações de cultura das lideranças funk.

Pois os órgãos governamentais buscavam um funk que não fosse nem a putaria aquele mesmo sub-gênero de funk carioca que arrasta multidões aos bailes e festas funk, conduzidos em comunidades e clubes massivamente freqüentados pelas classes populares 
ou em casas de shows e boates predominantemente buscadas pelas classes médias da cidade - nem o proibidão, que trata das ações ilícitas ou das relações com a polícia e que teve o seu auge em fins dos anos 1990 e início dos anos 2000. Ao mesmo tempo, lideranças como as da APAFunk (Associação dos Profissionais e Amigos do Funk), formada por artistas funk e em diálogo com intelectuais e outras lideranças políticas, argumentavam que o movimento musical estava fortemente marcado pelas pressões do mercado. Este traço tornaria o funk altamente dependente das forças hegemônicas e findaria por produzir uma música que seria, do referido ponto de vista, desengajada e pouco genuína. ${ }^{9}$

Duas são as vertentes do funk que são costumeiramente acusadas de cederem ao mercado. Uma delas é o que alguns chamam de pop funk e que outros questionam se o termo funk deve ainda nomear este sub-gênero musical uma vez que o mesmo já não teria mais os traços que fizeram um dia seus artistas serem a ele identificado. ${ }^{10}$ Os exemplos mais acionados são os MCs Anitta e Naldo. Este último adicionou Benny ao seu nome inicial na intenção de ganhar assim maior permeabilidade no mercado global de música.

Mas o grande vilão seria mais propriamente a putaria, o subgênero de funk distintivo não apenas de Mr. Catra mas de uma geração de artistas que para ela migraram oriundos do proibidão em busca de maior circulação para seu trabalhos. A grande permeabilidade e recepção do sub-gênero faria com que artistas que não rezassem pela cartilha do erotismo e da violência caíssem no ostracismo. A culpa, argumentam, não é tanto do artista funk mas de um "mercado" que lhes impõem um estilo e formata o seu produto.

Sem desprezar os poderes que possui o capital nas sociedades regidas pelo mercado, podemos seguir por uma chave de leitura outra. Ao colocarmos produção e consumo em uma relação de oposição retiramos, de um lado, toda e qualquer potência e agência do produtor, do músico, do artista, e de todo e qualquer poder do consumidor, do fruidor, que aceitaria sem qualquer julgamento crítico os produtos a eles impostos. Na verdade, podemos pensar a recepção e a criação do funk em um registro não dual e apreender o mercado não tanto como puramente coercitivo mas como aquele que concede o norte para que o artista produza suas inovações sem contudo fugir ao seu estilo e a seu público (MIZRAHI, 2010a, 2013b, 2014a). Pensamos assim em uma chave alternativa para notarmos que o artista funk produz diferença ao manipular o mercado e as diretrizes da indústria cultural. A relação entre mercado, artista e inovação pode assim ser considerada de uma perspectiva dialógica ao invés de exclusivamente determinista. De modo que as forças e as relações de poder funcionam em tensão e não de modo unívoco.

De toda maneira, a saída para a homogeneização que o mercado produziria poderia ser, como defendem alguns, um retorno aos raps de contexto, que produzem uma narrativa de

\footnotetext{
${ }^{9}$ Para essa discussão ver Facina e MC Leonardo (2009).

${ }^{10}$ Diferentes discussões na imprensa concernem esse tema. Ver por exemplo a seguinte matéria em: (MOURA, 2005).
} 
reconhecido teor político e que muitas vezes versa de maneira idílica e idealizada sobre a vida na favela. Incentiva-se a produção de canções em acordância com um sub-gênero que fundou o funk e esteve em sintonia com um determinado Rio de Janeiro, sensivelmente diferente daquele que adentra a segunda década dos anos 2000. O funk se transforma de acordo com a vida na cidade e no Brasil e, como veremos na próxima sessão, o tecido cultural atual corresponde a uma sonoridade e corporalidade particulares. Mas antes de passarmos a esta outra discussão temos alguns pontos a destacar.

Estimular a geração de produtos culturais a partir do que se entende como sendo "autêntico" e "genuíno" do funk apresenta continuidades com os processos de patrimonialização formais, na medida em que tem como raiz a imobilização de significados que estão por sua vez atrelados à construção de alguma subjetividade coletiva (GONÇALVES, 1988, 2005). Mais relevante para a nossa discussão, o retorno aos raps de contexto atende não apenas às demandas de suas lideranças como igualmente atende às políticas de cultura do governo do estado. Desse modo, a institucionalização e a legitimação do funk contribuem para que a noção oficial de cultura e a "cultura" das lideranças funkeiras passem a coincidir, o que reforça a ideia de que a legitimação do funk pode colaborar para a sua normatização colocando em risco seu aspecto subversivo.

No contexto da discussão sobre os usos e significados para a palavra cultura, Carneiro da Cunha (2009) diferencia uma noção com aspas e outra sem aspas. Em um momento de desgaste do uso do termo entre os antropólogos, os indígenas/nativos passam a agenciar "cultura" como categoria própria em suas reivindicações de cultura e etnicidade. A primeira noção, a cultura com aspas, corresponde ao dispositivo por meio do qual os povos cristalizam certos traços de sua cultura, a cultura sem aspas, que se refere ao sistema simbólico por meio do qual se situam no e apreendem o mundo. Contudo, é por meio da "cultura" que são feitas as reivindicações de etnicidade. Carneiro da Cunha dialoga com Sahlins (1997) que nota que, não obstante as críticas que o conceito de cultura viera recebendo de seus colegas pós-modernistas o mesmo passa a ser o próprio foro de constituição das identidades coletivas, seja em contextos interétnicos, seja ao ser integrada como forças do mercado e do capitalismo na própria estrutura de significado nativa. A "cultura" reaparece assim como a própria antítese de um projeto colonialista, uma vez que os povos a utilizam não apenas para marcar suas identidades mas para retomar as rédeas do próprio destino.

Mas se ao falarmos na institucionalização do funk, vemos a cristalização de uma cultura com aspas, é ao nos voltarmos para os sujeitos criativos que vemos em ação a invenção da cultura sem aspas. 


\section{Corpo, som e inventividade}

Nesse mesmo período começou a surgir muito espontaneamente o que os meus interlocutores em campo chamavam de "passinho foda", uma dança essencialmente masculina e individualizada, que envolvia sempre mais de um dançarino, cada um se exibindo para o outro e mostrando ao seu colega o seu virtuosismo. $O$ nome da dança fazia referência aos diferentes passos a comporem a coreografia, à grande destreza de seu executor e aos movimentos da dança. A dança e o dançarino eram assim "foda", termo que significa a potência do primeiro e indica o grau de complexidade do segundo. Essa nova voga no funk foi divulgada essencialmente através de vídeos caseiros postados no site de compartilhamento de imagens You Tube. Esta dança, ainda que seja composta parcialmente por movimentos sensuais, não é apreendida como sexualizada ou violenta. Não suprime os aspectos eróticos e violentos mas deixa-os implícitos, seja por meio da sonoridade da música que a acompanha, seja por meio do movimento corporal, que recorre frequentemente a um gestual sensual, erótico e jocoso. A música que acompanha a dança importa essencialmente em função de sua batida, de modo que a letra pode ser suprimida, sem fazer assim referência ao seu contexto de produção preferencial - a favela -, às ações ilícitas dos bandidos, à truculência da polícia ou à sexualidade explícita.

Os dançarinos do passinho elaboraram sobre dois aspectos essenciais ao funk, para além do conteúdo semântico de suas canções: o corpo e a sonoridade. Pois até este momento do texto, viemos abordando o funk essencialmente a partir das letras de suas músicas. Quero agora me deter sobre estes outros de seus aspectos, o som e o corpo, para passarmos à discussão sobre a inventividade no funk. Enfocaremos o modo pelo qual os sujeitos se apropriaram das demandas da sociedade para assim tornarem o funk mais permeável a ela sem contudo abrir mão de traços estilísticos que permitem recortar um gênero de música e que o distinguiram enquanto movimento estético-cultural.

O corpo no funk é central para a definição identitária do coletivo, seja no que toca à dança, seja no que diz respeito aos processos de auto-apresentação, seja ainda no que concerne as estratégias de visibilidade. Não é possível definir o sujeito funk e delinear sua correspondente noção de pessoa sem considerar o corpo em sua centralidade. A beleza e a aparência se mostram especialmente relacionadas às capacidades agentivas dos corpos e da pessoa. Define-se homem e mulher através da aparência e os investimentos sobre o corpo denotam inserção social e poder econômico. Além disso, vemos uma especial destreza no ato de se embelezar, seja nas habilidades desenvolvidas para tratar os cabelos e realizar penteados, seja na apuração do gosto indumentário. Diferentemente do que Bourdieu (1984) argumentou para as classes trabalhadoras na França, não é uma estética da falta que os jovens funks produzem nem tampouco é a um gosto da necessidade que eles atendem ao 
fazerem as escolhas de seus guarda-roupas e outros adereços corporais. Ao contrário, o que vemos é um esmero particular e um alto investimento, inclusive financeiro, sobre o corpo, acompanhados de apreço pelas marcas e pelos adornos, permitindo-nos pensar o consumo para além das noções de consumismo e de materialismo. Esses jovens são exemplares ao nos mostrarem como o consumo pode ser a produção de uma estética. Roupas, tênis, óculos, brincos, piercings, bonés, cabelos, maquiagem, unhas, sobrancelhas. Tudo é alvo de cuidado e elaboração. ${ }^{11}$

Por outro lado, no que diz respeito à sonoridade, temos o funk hoje se distanciando gradativamente do formato canção. Nas três letras de música que transcrevi mais ao início do artigo podemos notar que as duas primeiras constituem claramente uma narrativa. Elas nos contam uma história ou defendem algum ponto de vista. Por outro lado, a última destas letras, mais recente, mesmo que ainda forme uma narrativa é uma narrativa claramente curta, uma tendência que se afina com a ideia de que o funk vem abandonando as letras de música em seu formato tradicional para assumir-se como uma montagem. Dessa perspectiva, a palavra passa a ter sua importância questionada pela agência do som, de modo que seus sentidos semântico e descritivo passam a não ser mais os primordiais. Reproduzo abaixo a letra de uma música funk contemporânea.

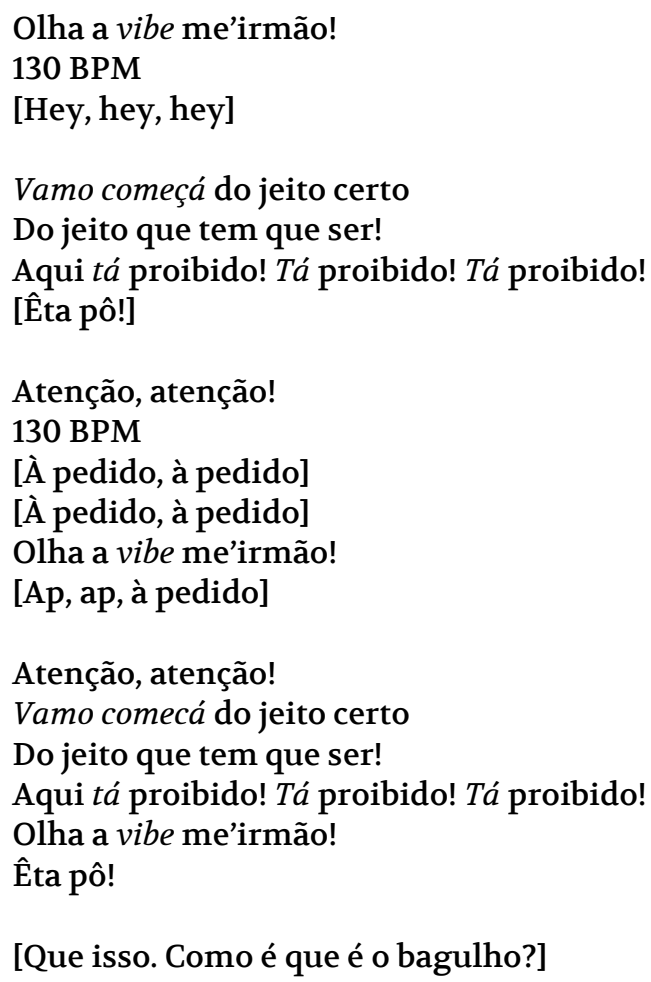

${ }^{11}$ Discorri sobre consumo e estéticas do corpo em diferentes ocasiões (MIZRAHI, 2006a, 2006b, 2007, 2008, 2009, 2010a, 2011, 2012a, 2012b, 2014a, 2014b). 


\author{
[Êta pô!] \\ [À-à-à-à-à-à, à pedido] \\ [À pedido, à pedido] \\ Olha a vibe me'irmão! \\ [Â pedido, à pedido, à pedido] \\ Pára tudo \\ Vamo comecá do jeito certo \\ Do jeito que tem que ser! \\ Aqui tá proibido! Tá proibido! ${ }^{12}$
}

Claramente não vemos aqui uma narrativa, mas uma montagem feita de palavras e trechos de outras músicas e samplers que são unidas, sobrepostas, gerando uma música outra na qual a palavra efetivamente não possui mais sentido descritivo e passa muitas vezes a cumprir o papel de som. A palavra, nas montagens, interessa muito mais enquanto sonoridade e não tanto a partir de seu significado lingüístico. O tipo de letramento que corresponde ao funk dos raps de contexto está hoje de fato mais próximo ao hip hop e seu discurso da denúncia que explicita por meio da palavra sua crítica à uma sociedade injusta à qual, contudo, se quer pertencer. O funk, diferentemente, quer se relacionar com a sociedade envolvente, mas quer fazer isso mantendo a diferença e sem deixar-se amalgamar. $O$ funk age conectivamente. ${ }^{13}$

Abaixo exponho a letra de uma música de rap que abre uma recente coletânea sobre o hip hop lusófono (MARTINS; CANEVACCI, 2015). O conteúdo de sua letra, além de sua extensão mostram, acredito, o quão contrastante ela é com o funk contemporâneo. Esses mesmo traços, por outro lado, permitem notar as continuidades que esta produção guarda com os raps de contexto.

Lusófona sou, saio trançando línguas E como hip hop volto em busca da cooperação Início meio fim, tradição, modernidade Cidadania de internacional dignidade

A arma atual, mais poderosa Já globalizada antes da era tecnológica Abro o diálogo, com os meios todos O mais forte instrumento, de comunicação

Atravesso oceanos, habito em continentes, Em várias línguas a mensagem sempre me transporta

\footnotetext{
${ }^{12}$ Olha a vibe, de Mr. Catra e produção de DJ Sandrinho. Arquivo sonoro em formato eletrônico cedido pelos artistas à pesquisadora.

${ }^{13}$ Esta discussão sobre a sonoridade no som sintetizada neste parágrafo e nos dois anteriores foi aprofundada no artigo "É o beat que dita: criatividade e não proeminência da palavra na Estética Funk Carioca" (MIZRAHI, 2010b).
} 
Para me tornar nobre, pertencer a uma raça Sofri influências ancestrais e da diáspora

Não fui colonizada como meus "patrícios Carrego várias referências e me orgulho disso Vivo em Portugal, Brasil, África, neste contexto Eu que visualizo e elaboro o texto

Movimento a mente, o pensamento da sociedade Resgato origens, dôo meu corpo aos descendentes Me viro na diversidade, social intervenção Elevo minha identidade e Nacionalização

A mim cabe a ingestão, preservação e resistência Nasci pluralizada em meio a muita treta Onde moro, os povos tem sua ciência Que não está dentro da academia de letras

Não aprovo preconceito, violência, discriminação No embate e no combate, não sou mole não Consagrada ferramenta de educação Sou tão forte, que formo a publica opinião

Denuncio machismo, racismo, sexismo, exclusão Tráfico de armas, de drogas e de pessoas A pobreza, e do capital a dominação Revelo conceitos, mas não tenho a conclusão

Sou o que sou, tenho raiz Em muitos lugares ainda estou pura Sou quem sou, uma andarilha Sou livre no mundo e vivo na rua

Começo como jovem e amadureço Olho para o povo o dia a dia de verdade Sou atriz principal, do meu próprio futuro Percebo a olhos nus, tamanha desigualdade

Transito nos espaços rurais e populares Enxergo a localidade e o que é necessidade Invado as periferias, diversos lugares Penso a estrutura, a paisagem da cidade

Posso ser simplesmente lazer, ou visual Onde vou, imponho a minha presença Arte sou, corpo sou, mente sou, som, Incômoda e ativa, faço a diferença

Onde ser humano, não é ser igual Pra população em vulnerabilidade Sou um indicador de pública política Especial, amada, odiada e crítica

Reconheço personalidades da atualidade Que chegaram depois das grandes ditaduras Que me usam como expressão de liberdade 
Contra regimes extremos, guerrilhas, tortura

To em becos e vielas, eu estou na rua

Nas segregações e nas grandes metrópoles

Nova minha forma de pensar, minha leitura

Esperando que a mídia não me dê um corte

Chega de confinamentos e conflitos territoriais

Meu perfil étnico, ainda hoje espanta

Me valorizo e me reconheço no outro

Minhas habilidades comuns e singulares encanta

Não quero ser apenas objeto de pesquisa

Idealizo novo panorama ignorado na literatura

Através de mim foi criada uma coletiva consciência

Para transmitir democraticamente minha cultura

Sou o que sou, tenho raiz

Em muitos lugares ainda estou pura

Sou quem sou, uma andarilha

Sou livre no mundo e vivo na rua ${ }^{14}($ MARTINS; CANEVACCI, 2015).

No funk contemporâneo a palavra não tem um sentido descritivo, como possui no hip hop. O que aparece de fato como primordial para os músicos funk é muito mais a agência do som do que a da palavra. Funk, dizem os artistas com os quais trabalhei, é antes de tudo som, "é o beat que dita". No hip hop, diferentemente, vemos músicas com letras extensas que denunciam e protestam por meio da palavra. Letras que não caberiam na musicalidade do funk contemporâneo. Uma "montagem" resultante de cortes, recortes, distorções e sobreposições de samplers de outras músicas.

Além disso, o artista funk elabora por meio das letras das músicas criativamente sobre "a realidade" da favela, sem contudo deixar que esta mesma realidade conceda a explicação para sua produção. É esta capacidade de ficcionar que responde pelo aspecto hiper-realista da estética funk, que exagera nas colorações do real. Dessa perspectiva, um retorno aos raps de contexto soaria incongruente tanto no que diz respeito ao contexto histórico-cultural de produção da música funk como quanto ao seu aspecto criativo e estético. Há uma relação estreita entre criatividade, estética e dado cultural.

Com a dança do passinho, por sua vez, o universo funk produziu uma linguagem que mesmo tornando-o permeável ao gosto oficial possibilitou-o a permanecer fiel a si mesmo. A novidade mostrou-se bastante atraente ao poder público e ao gosto oficial, e o seu nome foi transformado, passando de "passinho foda" para "dança do passinho do menor" e finalmente "dança do passinho". Alterações sutis como esta sobre o nome original da dança, que eliminou o elemento "proibido", nos falam sobre as ambigüidades envolvidas nos ${ }^{14}$ Livre no mundo, de Sharylaine, do álbum Sou Soul. Letra retirada do livro " Lusophone hip hop, who we are and
where we are: identity, urban culture and belonging". 
processos de invenção da cultura, no sentido dado por Wagner (1981) a este mecanismo, e de sua institucionalização. Mas o interessante é que o funk não se deixou aprisionar. Se trouxe ao público algo novo e mais adequado às demandas da sociedade envolvente, nem por isso deixou de lado suas marcas distintivas.

Permaneceu não subserviente mesmo atendendo à sociedade formal. Inovou sobre os mesmos elementos que tornaram sua estética distintiva: a centralidade do corpo, o caráter minoritário (porque não-hegemônico), a auto-apresentação, a importância da indumentária e outros elementos da cultura material corporal, o exibicionismo masculino e a sonoridade (MIZRAHI, 2007, 2010a, 2010b, 2014a). Os investimentos corporais são inúmeros: cabelos são tingidos e recortados, sobrancelhas são feitas, óculos de grau de armações coloridas, em cores especialmente intensas, são portados, roupas e tênis da moda são vestidos. $O$ corpo, mostram, é central para o seu sucesso, o que pode ser apreendido seja por meio da performance corporal ou sobre o que é colocado no corpo. ${ }^{15}$ Os objetos estendem as capacidades agentivas não apenas do corpo mas do sujeito, mostrando-nos que não é possível considerar corpo e objeto a partir de sua cisão mas de sua interconexão. O corpo se mostra em dança e em interação com a música, uma música que é puro som, com palavras eventuais, inseridas como mais um elemento sonoro, como são as montagens.

O concurso de dança A Batalha do Passinho (2011) foi criado pelo produtor cultural Rafael Mike e pelo escritor Julio Ludemir e a supressão dos elementos eróticos e violentos foi uma preocupação central de seus criadores de modo a potencializar o poder de penetração desta manifestação artística popular. Buscou-se visibilizar "[...] uma dança não apenas surpreendente do ponto de vista artístico, mas totalmente desvinculada do estereótipo sexista e violento que até então impedia o reconhecimento do funk como o principal símbolo de um Rio inventivo" [.... ${ }^{16}$ Em 2011, o SESC Tijuca - unidade do Serviço Social do Comércio localizada em um bairro que abriga diversas favelas - promoveu uma "batalha" oficial entre os dançarinos, com eliminatórias em três diferentes comunidades "pacificadas", iniciativa que teve o apoio mais uma vez do Instituto Pereira Passos, através da UPP Social, a outra faceta da política de pacificação do governo do estado em comunidades controladas pelo tráfico de drogas.

O funk está sim virando cultura, de um ponto de vista do que pode ser chamado de cultura pela sociedade formal, mas nem por isso deixou que as reivindicações de "cultura" diluíssem a diferença que o faz singular. Tampouco obedeceu à lógica apontada por Bourdieu (1984) que entende que a potência das produções estéticas das classes dominantes é tal que o real sempre se equivalerá ao oficial, como se a cultura fosse sempre com aspas. $\mathrm{O}$ funk é subversivo e funciona mais nos termos de Sapir (2012) para quem a cultura autêntica

\footnotetext{
${ }^{15}$ O documentário A batalha do passinho (2012) dá uma boa mostra do que são esses festivais e como a autoapresentação e os investimentos na estética corporal são centrais para o sucesso dos dançarinos e de suas performances.

${ }^{16}$ Trecho do texto descritivo na página do concurso Batalha do Passinho no Facebook.
} 
não é a que somente se reproduz, mas aquela que cria espaço para que as individualidades, as agências individuais, a alterem. A cultura genuína, segue o antropólogo norte-americano, não é aquela que imobiliza símbolos e significados primeiros mas a que se mantém em movimento e transformação graças às agencias individuais.

\section{Considerações finais}

Neste artigo procurei elaborar sobre o processo de legitimação que o funk carioca vem passando nos últimos anos. Por meio de uma argumentação que assume em alguns momentos um viés reflexivo, quis mostrar como somos muitas vezes capturados por este processo que guarda algumas semelhanças com os processos formais de patrimonialização de culturas. Somos capturados por esses processos de apropriação de significados e posterior conversão em representações de cultura mesmo que a eles não estejamos ativamente atentos.

Vimos que se os agentes oficiais e governamentais agem na seleção do que é ou não é cultura, vimos também que os sujeitos funk, por meio de suas reivindicações de "cultura" influenciam nesse processo. Foi-nos possível observar esta tensão em dois momentos: nas reivindicações de lideranças funk e na proposta que forjou o concurso A Batalha do Passinho. Os concursos que envolvem a Dança do Passinho do Menor nos colocaram em contato também com as estratégias de auto-apresentação imobilizadas pelo próprio sujeito criativo funk e no modo como ele se faz ver e inserir no espaço urbano carioca. A arte, as estéticas e as performances corporal constituem-se em estratégias de visibilização para a sociedade como um todo. Nossa análise evoluiu assim da música para o corpo.

Inicialmente mostrei como, a partir de minha própria inserção em campo e da minha produção acadêmica, estive sujeita, assim como estiveram meus interlocutores, às ambiguidades que envolvem esse processo de legitimação, mostrando como os aspectos erótico e violento, constitutivos do funk carioca, são os principais elementos a estimularem a ambivalência com que o movimento musical é recebido em ambientes oficiais. Em seguida mostrei que, na busca de uma maior circulação do funk ou de uma maior inserção de seus artistas, duas alternativas foram vislumbradas: um retorno aos raps de contexto ou uma adesão a um formato de mainstream da indústria musical, a música pop.

Por fim chegamos a uma terceira alternativa a partir de uma manifestação que emerge do tecido cultural fornecido pelo funk carioca, a dança conhecida como Passinho do Menor. A Dança do Passinho retém traços que são distintivos da socialidade funk, como a jocosidade, a sensualidade, a erotização, a vaidade masculina, a disputa. Esta dança, que só 
faz sentido quando envolve mais de uma parceiro, é encenada preferencialmente entre homens que disputam entre si para ver aquele mais hábil e o que possui maior destreza em seus movimentos. Foi a partir desses traços agonísticos que se criou A Batalha do Passinho, concurso que anualmente mobiliza parcela expressiva de jovens moradores das comunidades e favelas do Rio de Janeiro e enseja diversas etapas em diferentes comunidades.

Se o processo de institucionalização objetificou uma noção de cultura que fez coincidir reivindicações de identidade coletiva com demandas governamentais e suas políticas públicas, a própria dinâmica da cultura transformou o funk ao englobar a noção oficial de cultura, desetabilizando-a ao invés de reificá-la. As ambigüidades que derivam da seleção de significados e da ressignificação de sentidos foram incorporadas ao próprio processo de invenção da cultura a partir da criatividade do sujeito funk e de sua dinâmica inventiva. $O$ funk não se deixa aprisionar e para se legitimar não abre mão de seu ideais estéticos e cosmológicos.

\section{Bibliografia}

A BATALHA do passinho. Direção de Emílio Domingos. Rio de Janeiro: Osmose Filmes, 2012. Documentário.

BATALHA DO PASSINHO. Comunidade. Todo mundo no passinho. 2011. Disponível em: <https://www.facebook.com/batalhadopassinho/info?tab=page_info>. Acesso em: 11 maio 2015.

BOURDIEU, Pierre. Distinction: a social critique of the judgment of taste. London: Routledge and Kegan Paul, 1984.

CARNEIRO DA CUNHA, Manuela. Cultura com aspas e outros ensaios. São Paulo: Cosac e Naify, 2009.

CIDINHO; DOCA. Rap da felicidade. São Paulo: Universal Music, 2009. Web Hits, v. 1.

FORNACIARI, Christina. Funk da gema, de apropriação a invenção: por uma estética popular brasileira. Rio de Janeiro: FUNARTE, 2011.

FRANK, Mc; TICÃO, Mc. Encomenda. Disponível em:

<https://www.youtube.com/watch?v=RgnJxTpeh68>. 21 nov. 2007. Acesso em: 11 maio 2015. 
FRY, Peter. Feijoada e 'soul food': notas sobre a manipulação de símbolos étnicos e nacionais. In: _ _ _ _. Para inglês ver: identidade e política na cultura brasileira. Rio de Janeiro: Zahar, 1982. p. 47-53.

GONÇALVES, José Reginaldo. Autenticidade, memória e ideologias nacionais: o problema dos patrimônios culturais. Estudos Históricos, Rio de Janeiro, v. 1, fasc. 2, p. 264-2 75, 1988.

_. Ressonância, materialidade e subjetividade: as culturas como patrimônios.

Horizontes Antropológicos, Porto Alegre, v. 11, fasc. 23, p. 15-36, 2005.

MÁGICO, Mc. Hoje eu tô facinho. Disponível em:

<https://www.youtube.com/watch?v=vfkGFcc0jPY>. 30 jun. 2008. Acesso em: 11 maio 2015.

MARTINS, Rosana; CANEVACCI, Massimo. Lusophone hip hop, who we are and where we are: identity, urban culture and belonging. London: Sean Kingston Publishing, 2015.

MIZRAHI, Mylene. Figurino funk: uma etnografia sobre roupa, corpo e dança em uma festa carioca. Dissertação (Mestrado em Sociologia e Antropologia) -Universidade Federal do Rio de Janeiro, Rio de Janeiro, 2006a.

. A estética funk carioca: criação e conectividade em Mr. Catra. Tese (Doutorado em Sociologia e Antropologia) - Universidade Federal do Rio de Janeiro, Rio de Janeiro, 2010a. . A estética funk carioca: criação e conectividade em Mr. Catra. Rio de Janeiro: 7 Letras, 2014a.

. A moda funk: juventude, gênero e geração desenhando diferenças estilísticas. In: BARBOSA, L. (Org.). Juventudes e gerações no Brasil contemporâneo. Porto Alegre: Sulina, 2012b. v. 1, p. 211-237.

Brazilian jeans: materiality, body and seduction at a Rio de Janeiro's Funk Ball. In: MILLER, D.; WOODWARD, S. (Ed.). Global denim. Oxford: Berg, 2011. p. 103-126.

_ _ _ _ _ . Cabelos como extensões: relações protéticas, materialidade e agência na estética funk carioca. Textos escolhidos de cultura e arte populares (TECAP), Rio de Janeiro, v. 9, fasc. 2, p. 137-157, 2012a.

. É o beat que dita: criatividade e a não-proeminência da palavra na estética funk carioca. Desigualdade e Diversidade: Revista de Ciências Sociais da PUC-Rio, Rio de Janeiro, v. 7, fasc. 2, p. 175-204, 2010b.

. Figurino funk: a imbricação que a estética nos faz ver. In: GIUMBELLI, E.; DINIZ, J. C. V.; NAVES, S. C. Leituras sobre música popular: reflexões sobre sonoridades e cultura. Rio de Janeiro: Sete Letras, 2008. p. 121 -134. 
. Figurino funk: uma etnografia dos elementos estéticos de uma festa carioca. In: LEITÃO, D.; LIMA, D.; PINHEIRO-MACHADO, R. Antropologia e consumo: diálogos entre Brasil e Argentina. Porto Alegre: AGE, 2006b. p. 201-211.

. Indumentária funk: a confrontação da alteridade colocando em diálogo o local e o cosmopolita. Horizontes Antropológicos, Porto Alegre, v. 13, fasc. 28, p. 231-262, 2007.

. Mulher já nasce veada: estética, gênero e pessoa no Brasil urbano. Version:

Estudios de Comunicacion y Politica, México, v. 33, p. 119-131, $2014 \mathrm{~b}$.

. No Brasil tudo acaba em funk: indústria cultural, criatividade e agência em um movimento urbano. Curso Livre de Folclore e Cultura Popular. Centro Nacional de Folclore e Cultura Popular, 2013b. Palestra.

. O figurino funk e a sedução: a roupa, o corpo e a dança na esfera da festa.

Interseções, Rio de Janeiro, v. 11, n. 1, p. 149-171, 2009.

. Rio de Janeiro, uma cidade ciborgue. Cadernos do Desenvolvimento Fluminense, Rio de Janeiro, v. 1, p. 141-161, 2013a.

MOURA, Ananda. Empresária se especializa em transformar artistas do funk, como Anitta e Naldo em astros. O Globo, Rio de Janeiro, 19 abr. 2005. Disponível em:

$<$ http://oglobo.globo.com/rio/bairros/empresaria-se-especializa-em-transformar-artistasdo-funk-como-anitta-naldo-em-astros-2-15898736>. Acesso em: 11 maio 2015.

SAHLINS, Marshall. O pessimismo sentimental e a experiência etnográfica: por que a cultura não é um 'objeto' em via de extinção (parte I). Mana, Rio de Janeiro, v. 3, fasc. 1, p. 4173, 1997.

SAPIR, Edward. Cultura 'autêntica' e 'espúria'. Sociologia e Antropologia, Rio de Janeiro, v. 2, fasc. 4, p. 35-60, 2012.

STRATHERN, Marilyn. Partial connections. 2. ed. Lanham: Altamira Press. 2004.

WAGNER, Roy. The invention of culture. Chicago: University of Chicago Press, 1981. 